\title{
Persepsi Ibu Bayi atau Ibu Balita terhadap Posyandu (Studi Kualitatif Pendekatan Fenomenologi)
}

\author{
Norfai $^{1}$, Eddy Rahman ${ }^{2}$, Abdullah $^{3}$ \\ ${ }^{1,2,3}$ Fakultas Kesehatan Masyarakat Universitas Islam Kalimantan Muhammad Arsyad Al Banjari \\ Banjarmasin \\ *Email : $\underline{\text { norfai92@gmail.com }}$
}

Submitted : 25/03/2021

Accepted: 10/09/2021

Published: 15/09/2021

\begin{abstract}
This research is a qualitative research with a phenomenological approach. Determining the number of informants used in qualitative research consists of two considerations, namely suitability and adequacy. The suitability in this case is that the researcher uses purposive sampling, where the researcher determines the informant according to the criteria, which means that the informant is able to provide information in accordance with the research objectives. Adequacy refers to the number of informants consisting of 5 to 8 participants, with a note that there are no more significant variations in answers from one source to another data source or saturation, if it does not reach saturation, then the selection of informants will continue. The data was collected by means of in-depth interviews using interview guidelines consisting of open-ended questions and a voice recorder as a tool to record all information that has been conveyed by the informants. Data processing and analysis were carried out by transcription, finding keywords, creating categories, grouping categories into sub-themes, formulating themes and continued by integrating the results of the analysis into descriptive form. Still not fully understanding about the posyandu program, it is necessary to strengthen the role of posyandu cadres by conducting intensive coaching and there needs to be adequate incentives for cadres in an effort to increase the cadres' motivation.
\end{abstract}

Keywords : perception of mother who have babies, mother who have children under five years, posyandu

\begin{abstract}
Abstrak
Penelitian ini merupakan penelitian kualitatif dengan pendekatan fenomenologi. Menentukan jumlah informan yang digunakan dalam penelitian kualitatif terdiri dari dua pertimbangan yaitu kesesuaian dan kecukupan. Kesesuaian dalam hal ini adalah peneliti menggunakan purposive sampling, dimana peneliti dalam menentukan informan sesuai dengan kriteria yang berarti informan tersebut mampu memberikan informasi sesuai dengan tujuan penelitian. Kecukupan yang dimaksudkan adalah jumlah informan terdiri dari 5 sampai 8 partisipan, dengan catatan tidak ada lagi variasi jawaban yang cukup menonjol antara satu sumber dengan sumber data lainnya atau saturation, apabila tidak mencapai saturation, maka pemilihan informan terus dilanjutkan. Pengumpulan data dilakukan dengan cara wawancara secara mendalam atau indepth interview menggunakan menggunakan pedoman wawancara yang tediri dari pertanyaan-pertanyaan terbuka dan alat perekam suara sebagai alat bantu untuk merekam semua informasi yang telah disampaikan oleh informan. Pengolahan dan analisis data dilakukan dengan cara melakukan transkripsi, menemukan kata kunci, membuat kategori, mengelompokkan kategori kedalam subtema, merumuskan tema dan dilanjutkan dengan mengintegrasikan hasil analisis ke dalam bentuk deskriptif. Masih belum memahami secara keseluruhan terhadap program posyandu, maka perlu adanya penguatan peran kader posyandu dengan cara melakukan pembinaan secara itensif, memberikan pelatihan secara berkala kepada kader posyandu serta perlu adanya insentif yang memadai bagi kader dalam upaya meningkatkan motivasi kader tersebut.
\end{abstract}

Kata kunci : persepsi ibu bayi, ibu balita, posyandu 


\section{PENDAHULUAN}

Posyandu merupakan perwujudan dari Upaya Kesehatan Bersumber Daya Masyarakat (UKBM), dimana kegiatan Posyandu dikelola dan diselenggarakan dari, oleh, untuk dan bersama rakyat dalam memberdayakan masyarakat serta memudahkan masyarakat dalam mendapatkan pelayanan kesehatan dasar dalam upaya menjaga eksistensi dari peran Posyandu yang berada di tengah-tengah masyarakat. Posyandu mampu menjalankan tugas dan fungsinya di tengah masyarakat, tidak terlepas dari semua komponen yang ada di masyarakat seperti peran kader serta stakeholder (Kemenkes RI, 2012).

Salah satu upaya untuk mengurangi angka kesakitan dan kematian balita adalah dengan melakukan pemeliharaan kesehatannya. Pemeliharaan kesehatan anak balita dititik beratkan kepada upaya pencegahan dan peningkatan kesehatan serta pengobatan dan rehabilitasi yang dapat dilakukan di Puskesmas, Puskesmas Pembantu, Polindes dan di Posyandu, karena pada dasar Posyandu merupakan sarana kesehatan dalam memberikan pelayanan kesehatan bagi bayi, balita, ibu hamil dan Pasangan Usia Subur (PUS) (Nain, 2008).

Kunjungan balita di Posyandu berkaitan dengan peran ibu sebagai orang yang paling bertanggungjawab terhadap kesehatan balita, karena balita sangat bergantung pada ibu. Alasan utama ibu membawa balita ke Posyandu karena ingin anak mendapatkan pelayanan kesehatan yang maksimal. Oleh karena itu, ibu mempunyai peranan penting terhadap keaktifan kunjungan ke Posyandu, sehingga perlu kerjasama semua pihak dan stakeholder dalam upaya membangun motivasi dari ibu balita tersebut (Farida, 2012 dalam Wardani, dkk., 2015).

Cakupan penimbangan balita di Posyandu (D/S) merupakan indikator yang berkaitan dengan cakupan pelayanan gizi pada balita, cakupan pelayanan kesehatan dasar khusunya imunisasi serta prevalensi gizi kurang. Semakin tinggi cakupan D/S, semakin tinggi cakupan vitamin A, semakin tinggi cakupan imunisasi dan semakin rendah prevalensi gizi kurang. Keberhasilan Program posyandu, salah satunya adalah keaktifan ibu bayi dan balita dalam melakuakn kunjungan ke Posyandu secara rutin sebulan sekali minimal delapan kali selama satu tahun (Kemenkes RI, 2012).

Secara kuantitas, perkembangan jumlah posyandu terus meningkat, dimana pada tahun 2009 terdapat sebanyak 266.827 Posyandu dengan rasio 3,55 Posyandu per desa/kelurahan yang artinya bahwa setiap desa/kelurahan terdapat 3 sampai 4 Posyandu, akan tetapi dilihat dari aspek kualitas terdapat beberapa kekurangan seperti kelengkapan sarana yang belum memadai dan kurangnya keterampilan kader Posyandu, oleh sebab itu keberhasilan Posyandu tidak terlepas dari dukungan berbagai pihak, berupa dukungan moril, materil maupun finansial (Kemenkes RI, 2011).

Persepsi warga masyarakat terhadap kegiatan program tertentu merupakan landasan atau dasar utama bagi timbulnya kesediaan untuk ikut terlibat dan berperan secara aktif dalam setiap kegiatan program tersebut. Makna positif atau negatif sebagai hasil persepsi seseorang terhadap program akan menjadi pendorong atau penghambat baginya untuk berperan dalam kegiatannya (Davidoff, 1988 dalam Wiratmoko, 2006).

Berbagai hal yang terjadi dan menjadi pengalaman yang kurang menyenangkan sering mengakibatkan warga masyarakat kurang bersikap terbuka untuk secara jujur menyatakan persepsi dan pandangannya tentang suatu program kegiatan yang secara resmi diselenggarakan oleh pemerintah. Karena sering dilandasi oleh persepsi yang kurang positif maka keterlibatan yang ada sering merupakan partisipasi semu. Keadaan demikian itu bila terjadi, sering membawa akibat kurang lancarnya kegiatan sesuai dengan rencana sehingga 
menyulitkan usaha pencapaian tujuan program secara utuh dan mantap (Sutopo, 1996 dalam Wiratmoko, 2006).

Selama ini banyak program pemerintah dalam usaha pengembangan masyarakat telah dirancang dan diputuskan hanya berdasarkan konsep, dan pertimbangan dari atas (top down), tanpa memperhatikan kekhususan latar belakang sosial, ekonomi, dan budayanya, yang sangat memungkinkan terjadinya perbedaan persepsi antarwarga masyarakat terhadapnya yang berakibat banyak program menghadapi kendala dalam pelaksanaannya, terutama dalam mengembangkan partisipasi aktif masyarakat sebagai komponen utama dalam mencapai keberhasilan program. Kegagalan dalam mengembangkan partisipasi aktif warga masyarakat tersebut selama ini tidak banyak dijelaskan, karena proses interaksi warga masyarakat serta makna persepsinya terhadap kegiatan yang sedang dikembangkan, yang sebenarnya sangat dipengaruhi oleh kekhususan kondisi sosial ekonomi dan budayanya tak banyak menjadi sasaran pengkajian secara teliti dalam proses perencanaan program (Lestari, 2007).

Persepsi masyarakat terhadap program posyandu, tidak hanya dilihat sebagai proses penerimaan stimulus dari luar dirinya, akan tetapi sikap psikis masyarakat dalam memahami urgensi pelaksanaan program posyandu yang diselenggarakan oleh pemerintah yang lebih bermakna. Persepsi positif masyarakat terhadap program posyandu, akan sangat menentukan terhadap partisipasi aktif masyarakat dalam pelaksanaan program posyandu secara berkesinambungan (Lestari, 2007).

Berdasarkan fenomena tersebut menunjukkan bahwa persepsi atau sudut pandang masyarakat mengenai posyandu masih sempit, dimana pandangan masyarakat selama ini mengenai posyandu yang sempit yaitu ibu yang melakukan penimbangan balitanya selain itu kurang memahami akan pentingnya keberadaanya posyandu ditengah-tengah masyarakat, oleh sebab itu penulis perlu melakukan penelitian dengan judul "Persepsi Ibu Bayi atau Ibu Balita terhadap Posyandu (Studi Kualitatif dengan Pendekatan Fenomenologi)".

\section{METODE PENELITIAN}

Penelitian ini merupakan penelitian kualitatif dengan pendekatan fenomenologi. Menentukan jumlah informan yang digunakan dalam penelitian kualitatif terdiri dari dua pertimbangan yaitu kesesuaian dan kecukupan. Kesesuaian dalam hal ini adalah peneliti menggunakan purposive sampling, dimana peneliti dalam menentukan informan sesuai dengan kriteria yang berarti informan tersebut mampu memberikan informasi sesuai dengan tujuan penelitian. Kecukupan yang dimaksudkan adalah jumlah informan terdiri dari 5 sampai 8 partisipan, dengan catatan tidak ada lagi variasi jawaban yang cukup menonjol antara satu sumber dengan sumber data lainnya atau saturation, apabila tidak mencapai saturation, maka pemilihan informan terus dilanjutkan. Pengumpulan data dilakukan dengan cara wawancara secara mendalam atau indepth interview menggunakan menggunakan pedoman wawancara yang tediri dari pertanyaanpertanyaan terbuka dan alat perekam suara sebagai alat bantu untuk merekam semua informasi yang telah disampaikan oleh informan. Pengolahan dan analisis data dilakukan dengan cara melakukan transkripsi, menemukan kata kunci, membuat kategori, mengelompokkan kategori kedalam subtema, merumuskan tema dan dilanjutkan dengan mengintegrasikan hasil analisis ke dalam bentuk deskriptif.

\section{HASIL DAN PEMBAHASAN}

Berdasarkan hasil wawancara kepada informan mengenai tanggapan ibu terhadap 
Posyandu Kenanga yang terdapat di wilayah kerja Puskesmas Kuin Raya kota Banjarmasin, dimana posyandu tersebut terdapat ditengah-tengah masyarakat, didapatkan sebagian besar mengatakan bahwa posyandu sangat membantu dalam memantau pertumbuhan dan perkembangan bayi dan balita. Ibu balita sebenarnya memahami peran posyandu di tengahtengah masyarakat, apalagi di masa pandemik sekarang ini, dimana kader posyandu turun langsung kelapangan untuk berkunjung kerumah ibu balita dalam rangka memantau pertumbuhan dan perkembangan balita serta sebagian besar informan mengatakan bahwa pelayanan yang diberikan oleh posyandu sangat baik, kadernya ramah dalam memberikan edukasi, hal inilah yang membuat ibu balita merasa puas terhadap pelayanan yang diberikan, akan tetapi dalam aspek pengetahuan mengenai program posyandu didapatkan bahwa sebagaian besar informan masih belum memahami secara utuh mengenai program yang terdapat didalam posyandu tersebut, karena persepsi selama ini, posyandu dianggap hanya sebagai tempat pengukuran pertumbuhan dan perkembangan balita seperti penimbangan balita, kegiatan imunisasi pemberian vitamin, pemberian obat cacing dan pelayanan $\mathrm{KB}$, padahal kegiatan posyandu bukan hanya sekedar itu, akan tetapi kegiatan yang mencakup kegiatan utama dan kegiatan pengembangan, dimana kegiatan pengembangan dapat dilakukan apabila kegiatan utama dari posyandu tersebut sudah berjalan sebagai mana mestinya, setidaknya kegiatan utama sudah terlaksana sebesar lebih dari 50\% dan mendapatkan sumber daya yang dapat mendukung kegiatan tersebut. Harapan kedepannya untuk posyandu sebagian besar menyatakan bahwa agar para kader posyandu serta petugas kesehatan tetap melakukan kunjungan kerumah-rumah ibu balita, karena hal ini sangat membantu bagi ibu balita yang mempunyai kesibukan seperti bekerja dan kesibukan sebagai Ibu Rumah Tangga (IRT).

Berdasarkan fenomena tersebut didapatkan temuan bahwa peran kader begitu penting dimasyarakat dalam upaya mensukseskan program posyandu, oleh sebab itu perlu adanya perhatian khusus dalam upaya meningkatkan kualitas dari kader posyandu tersebut, dengan cara melakukan pembinaan dalam upaya meningkatkan keterampilan mengelola posyandu serta perlunya insentif yang memadai bagi para kader posyandu sebagai motivasi kader tersebut, karena memang tidak mudah menjalankan tugas sebagai kader posyandu, apalagi di masa pandemik sekarang, dimana kegiatan posyandu dilakukan dengan cara para kader posyandu berkunjung kerumah-rumah ibu balita, hal ini lah yang perlu diperhatikan pemerintah terkait agar pelaksanaan posyandu dapat dilaksanakan secara optimal, karena betapa pentingnya peran posyandu di masyarakat, dimana tujuan utamanya adalah penurunan Angka Kematian Ibu (AKI) dan Angka Kematian Bayi (AKB) di Indonesia melalui upaya pemberdayaan masyarakat. Sasaran dari pelayanan posyandu ialah seluruh masyarakat terutama bayi, balita, ibu hamil, ibu menyusui, ibu nifas, serta Wanita Usia Subur (WUS) dan Pasangan Usia Subur (PUS). Pengoptimalan posyandu memungkinkan untuk dapat menekan angka kejadian stunting pada balita, oleh sebab itu sebagai langkah awal dalam pengoptimalan kegiatan posyandu adalah perlu adanya penguatan peran kader posyandu, karena kader posyandu sebagai motor penggerak kesehatan masyarakat yang dapat menjadi komunikator yang baik dalam menyebarkan informasi kesehatan kepada masyarakat mengenai informasi kesehatan ibu dan anak secara tepat. Dimana penguatan kader posyandu dapat dilakukan dengan cara melakukan pembinaan oleh petugas kesehatan puskesmas dalam pengelolan posyandu secara baik. 
Sejalan dengan penelitian yang dilakukan Djamil (2017) didapatkan analisis bivariat menunjukkan $p$ value $=0,010$, yang berarti bahwa ada hubungan yang signifikan antara dukungan kader dengan perilaku ibu balita dalam menimbang anaknya ke posyandu di wilayah kerja UPT Puskesmas Way Panji Kabupaten Lampung Selatan tahun 2016, sedangkan nilai $\mathrm{OR}=3,435$, artinya ibu balita yang mendapat dukungan dari kader dengan baik mempunyai peluang berperilaku baik dalam menimbang anaknya ke posyandu sebesar 3,43 kali dibandingkan dengan ibu balita yang mendapat dukungan kader dengan buruk.

Peran kader yang optimal memungkinkan untuk membentuk persepsi ibu balita menjadi positif terhadap posyandu, kemudian apabila persepsi ibu sudah terbentuk secara positif mengenai posyandu, maka akan berdampak terhadap perilaku kunjungan ibu ke posyandu. Sejala dengan penelitian yang dilakukan Trisnawati (2011) didapatkan bahwa terdapat hubungan antara persepsi ibu tentang posyandu dengan perilaku kunjungan balita ke posyandu Mawar di Dusun Soragan Ngestiharjo Kasihan Bantul Yogyakarta.

\section{SIMPULAN}

Berdasarkan hasil wawancara dengan informan didapatkan bahwa keberadaan posyandu mempunyai tanggapan yang positif, dimana sebagian besar mengatakan bahwa posyandu sangat membantu dalam memantau pertumbuhan dan perkembangan anak dan merasakan kepuasaan terhadap pelayanan yang diberikan oleh kader posyandu, karena di masa pandemic sekarang ini, para kader posyandu melakukan kunjungan ke rumahrumah ibu balita.

\section{SARAN}

Pihak puskesmas perlu meningkatkan pembinaaan kepada para kader posyandu dalam upaya meningkatkan kemampuan dalam pengelolaan posyandu serta perlunya perhatian dari pihak pemerintah terkait, agar dapat memberikan insentif yang memadai kepada kader, karena kader merupakan motor penggerak dari kegiatan posyandu tersebut, sehingga dengan adanya insentif yang memadai dapat mampu meningkatkan motivasi kader posyandu tersebut.

\section{UCAPAN TERIMA KASIH}

Penulis mengucapkan terima kasih kepada Lembaga Penelitian dan Pengabdian pada Masyarakat (LP2M) Universitas Islam Kalimantan Muhammad Arsyad Al Banjari Banjarmasin yang telah memberikan dana penelitian APBU dan Kepala Puskesmas Kuin Raya Kota Banjarmasin yang telah memberikan izin untuk melaksanakan kegiatan penelitian serta petugas kesehatan Puskesmas Kuin Raya Kota Banjarmasin dan kader posyandu Kenanga yang telah membantu dalam kelancaran kegiatan penelitian ini.

\section{DAFTAR PUSTAKA}

Alizamar dan Couto, Nasbahry., 2016. Psikologi Persepsi \& Desain Informasi; Sebuah Kajian Psikologi Persepsi dan Prinsip Koginitif untuk Kependidikan dan Desain Komunikasi Visual. Edisi Pertama, Cetakan Ke-1. Yogyakarta; Media Akademi.

Djamil, Achmad., 2017. Jurnal Kesehatan. Faktor-Faktor yang Berhubungan dengan Perilaku Ibu Balita Menimbang Anaknya ke Posyandu, Vol. VIII, No. 1 April.[Online]. https://ejurnal.poltekkestjk.ac.id/index.php/JK/article/view/4 09. [di akses tanggal 25 Maret 2021].

Juanda, Firyal Afifah, Arifin, Syamsul, Lestari, Dhian Ririn., 2014. Dunia Keperawatan (Jurnal Keperawatan dan Kesehatan). Faktor yang 
Berhubungan dengan Kunjungan Ibu Balita ke Posyandu di Kelurahan Palam Kecamatan Cempaka Banajarbaru Tahun 2013. Vol. 2, No. 1. [Online]. http://ppjp.unlam.ac.id/journal/index .php/JDK/article/view/3370. [di akses tanggal 29 November 2020].

Kemenkes RI, 2011. Pedoman Umum Pengelolaan Posyandu: Jakarta. [Online].https://cisdi.org/files/9f1f5 3a8c4b972590cfb79d815d48ceaf76 e0f16.pdf. [di akses tanggal 29 November 2020].

Kemenkes RI, Pusat Promosi Kesehatan, 2012. Buku Saku Posyandu : Ayo ke Posyandu Setiap Bulan, Posyandu menjaga Anak dan ibu Tetap sehat. [Online].http://www.depkes.go.id/re sources/download/promosikesehatan /buku-saku-posyandu.pdf. [diakses tanggal 29 November 2020].

Lestari, Puji., 2007. Dimensia: Jurnal Kajian Sosiologi. Persepsi dan Partisipasi Masyarakat Desa Giritirto Kecamatan Purwosari Gunung Kidul terhadap Kegiatan Program Posyandu. Vol. I, No. 1 Maret. [Online]. https://journal.uny.ac.id/index.php/d imensia/article/view/3394. [di akses tanggal 29 November 2020].

Marniati, 2012. Tesis. Pengaruh Faktor Predisposisi, Pendukung dan Kebutuhan Ibu Balita Terhadap Pemanfaatan Posyandu di Wilayah Kerja Puskesmas Alue Bilie Kecamatan Darul Makmur Kabupaten Nagan Raya. Program, Studi S2 Ilmu Kesehatan Masyarakat, Fakultas Kesehatan Masyarakat, Universitas Sumatera Utara.

[Online]. http://repository.usu.ac.id/handle/12 3456789/33522. [diakses tanggal 29 November 2020].

Nain, U., 2008. Posyandu : Upaya Kesehatan Berbasis Masyarakat. Yogyakarta:Kareso.

Saepudin, Encang., Rizal, Edwin dan Rusman, Agus., 2017. Record and Library Journal. Peran Posyandu sebagai Pusat Informasi Kesehatan Ibu dan Anak. Vol. 3, No. 2 JuliDesember 2017. [Online]. https://ejournal.unair.ac.id/RLJ/article/view/ 7338. [diakses tanggal 30 November 2020].

Trisnawati, 2011. Naskah Publikasi. Hubungan Persepsi ibu tentan Posyandu dengan Perilaku Kunjungan Balita ke Posyandi Mawar di Dusun Soragan Ngestiharjo Kasihan Bantul Yogyakarta. Program Studi Ilmu keperawatan Sekolah Tinggi Ilmu Kesehatan 'Aisyiyah Yogyakarta.

Wardani, Dian Palupi Kusuma, Sari, Sheizi Prista dan Nurhidayah, Ikeu., 2015. Hubungan Persepsi dengan Perilaku Ibu Membawa Balita ke Posyandu. Vol. 3, No. 1 April. [Online].

jkp.fkep.unpad.ac.id/index.php/jkp/a rticle/download/93/88. [diakses tanggal 1 Desember 2020].

Wiratmoko, Dheny., 2006. Pelita-Jurnal Penelitian Mahasiswa UNY. Persepsi dan Partisipasi Masyarakat terhadap Program Posyandu. Vol. I, No. 2 Mei 2006.[Online].https://journal.uny.ac. id/index.php/pelita/article/view/433 2/3753. [diakses tanggal 29 November 2020]. 